\title{
A Health Model Based on the Clinical Practice of Manual Therapists
}

\author{
Santos $\mathrm{L}^{{ }_{1}}$, Santos $\mathrm{PC}^{1}$, and Cruz $\mathrm{EB}^{2}$ \\ ${ }^{1}$ ESTSP, School of Health Technology of Porto, Portugal \\ ${ }^{2}$ IPS-ESS, Polytechnic Institute of Setúbal, School of Health, Portugal
}

*Corresponding author: Santos L, ESTSP, School of Health Technology of Porto, Portugal, Tel: 914984362, E-mail: lianepinhosantos@hotmail.com

Citation: Santos L, Santos PC, Cruz EB (2018) A Health Model Based on the Clinical Practice of Manual Therapists. J Nutr Health Sci 5(3): 305. doi: 10.15744/2393-9060.5.305

Received Date: May 01, 2018 Accepted Date: September 12, 2018 Published Date: September 14, 2018

\begin{abstract}
Introduction: The evolution of health models occurred along with the changes of the definition of health and rehabilitation but it is still unknown the predominant model of health that fits the clinical practice of physiotherapists who work in manual therapy.

$\operatorname{Aim}(s)$ : Creation of a questionnaire to assess the health model that fits the clinical practice of physiotherapists and after application, verify the knowledge of healthcare models, the degree of agreement between the health model in which physiotherapists based clinical practice and the attitudes and beliefs of physiotherapists in the face of biomedical and biopsychosocial orientation (PABS-PT) and verify the profile and attitudes and behaviors of physiotherapists are related to the health care model.
\end{abstract}

Methods: Cross-sectional analytical quantitative study with 203 manual therapists. For the construction of the questionnaire were measured content validity and an accomplished pilot study of reliability. The questionnaire was available for 40 days. Data analysis used the chi-square test, the ordinal correlation coefficient of Spearman and descriptive analysis.

Results: Physiotherapists consider that clinical practice is based on the holistic model. This model and the biopsychosocial model is the best-known models, opposite to the ecological model. On the intervention, evaluation directed greater attention to physical symptoms, medical history and causes of the condition, report that work and give more importance to the biological and physical component. After reading the definition of health model, the holistic model stood out. By analyzing the attitudes and beliefs, who referred to the biomedical model as a basis, has increased awareness of the model itself. The choice of model is independent of the profile of physical therapists.

Conclusion: Physiotherapists consider their clinical practice is based on the holistic model, however, maintain intervention and evaluation focused on the biomedical model.

Keywords: Physiotherapy; Orthopedic Manual Therapy; Clínical Practice Models

\section{Introduction}

Physiotherapy is an established and regulated profession, with specific professional characteristics in education and clinical practice. The extensive knowledge of the body and its movements are crucial competences of physiotherapists for determining the diagnosis and strategies for therapeutic in different areas with specific procedures, techniques, methodologies and approaches. The type of intervention changes according to the context and to the intervention's objective, either it be promotion of health, prevention of pathology or (re)abilitation [1], as the Manual Orthopaedic Therapy, Neurology, Cardiorespiratory, Community, Sport, Geriatric, Women's health, Paediatric, Amputees [2].

Orthopedic Manual Therapy or just, Manual Therapy was the basis for the development of physiotherapy as a profession. The hands became an instrument of knowledge and a therapeutic tool, playing a fundamental role in the evaluation, diagnosis and intervention of pathologies [3]. Manual therapy is an area of physiotherapy specialized in neuro-muscle-skeletal conditions based on clinical reasoning, using highly specific treatment approaches, including manual technique and therapeutic exercises [4]. It is represented worldwide by the International Federation of Orthopaedic Manipulative Physical Therapists (IFOMPT) and recognized as a subgroup of the World Confederation for Physical Therapy (WCPT) [5].

The concept of rehabilitation "It is a global and dynamic process oriented towards the physical and psychological recovery of a person with a disability, with a focus on their social reintegration". "It is associated with a broader concept of health, incorporating physical, psychological and social well-being that all individuals have a right to" [6] fits in with the concept of health, as "capacity to adapt and self-manage", where three domains must be identified: physical, mental and social $[7,8]$. 
The existent health models provide the basis for clinical practice, with different forms of action and conditionals [6]. Historically, intervention in physical therapy/manual therapy has been guided by the biomedical model $[9,10]$. This model focuses on obtaining specific objective conclusions that are interpreted as the cause of the disease and it should be eliminated by the physiotherapist [12]. This model has limitations because it doesn't consider the individual as a whole [13].

After the beginning of the 20th century and with the advances in medicine, it was verified that the biomedical model doesn't give conclusive or satisfactory answers to many pathologies, especially non transmissible chronical diseases or to the subjective components that accompany it $[10,14-20]$.

Thus, it was necessary to conceptualize a new model which includes the interdependence of physical, cognitive, affective, behavioral and psychosocial factors in health and pathology of the user [19,21-23], the biopsychosocial model [24,10]. This model recognizes the user as a whole $[21,25]$, in its social, cultural and environmental context and its influence on the response of an individual to the pathology. In other words, the interventions performed are patient-centered and any discussion of therapeutic decisions begins with their perspective $[12,21,26]$.

Physiotherapists recognize the multidimensionality of pathologies and attempt to integrate physical and psychosocial components, but most feel more confident solving physical symptoms [10,21], as their academic training is based on the biomedical model, which is more focused on neuro-musculo-skeletal issues [10,27].

The application of the biopsychosocial model has led to a growing interest in approaches combining physical exercises as well as exercises based the cognitive-behavioural model, where the objective is to help people learn how to think, to change their own perception and to adapt their own behaviour $[19,28,29]$. According to this model, the way an individual thinks produces emotions, including associated physical sensations which influence their behavior [30]. This model is insufficient by itself, but it's quite useful as a complement to other models [26,31].

The holistic model is also a variant of the biopsychosocial model, in which rehabilitation is considered a process of problem solving. It focuses on individual's activities in order to optimize social participation [33], combined with promotion and prevention of health [32]. The holistic model is based on a view of man as a whole [32,34,35], and is defined as the interrelation between body, mind and spirit, as well as the interconnection of the individual with his social and cultural environment [36]. In the intervention based on this model, the user is seen as autonomous and able to develop self-empowerment in order to deal with the pathology [32], being in conformity with the health definition [37].

Recently, with the evolution of health models, there has been increasing interest in the ecological model because the World Health Organization (WHO) reported that different levels of health are useful for the conceptualization of causes, effects and interventions for different problems of community health [38]. This model got attention and interest for it includes environmental, sociocultural and political factors, which are known to influence individuals' behaviour. Instead of accepting that behaviour is influenced only by psychosocial factors, the ecological model is influenced by different factors of the various health levels. These levels include intrapersonal, interpersonal/cultural, organizational/ institutional, environmental and political factors [39,40-47].

The various health models overlap in certain areas, due to the physiotherapist's clinical practice being guided by the user and their condition, hence, adaptations must be made accordingly.

Nowadays, considering the changes in health and rehabilitation definitions and that the evolution in health models provides the basis for clinical practice [9,21], it becomes pertinent to understand which health model physiotherapists that work in manual therapy, base their own clinical practice. However, with the lack of an evaluation tool to verify it, a questionnaire was used to collect the information.

In this way, the study objectives are (i)-the construction of a questionnaire in order to ascertain which health model best fits the clinical practice of physiotherapist' who work with manual therapy; (ii)-to identify the health model that best fits the clinical practice of physiotherapists who work with manual therapy; and (iii)-Verify physiotherapists' profile, knowledge, attitudes and behaviours related to the care practice model.

\section{Methods}

\section{Study Design}

The present study is a cross analytic quantitative study.

\section{Sample}

The study group includes 203 manual therapists. The questionnaire was disseminated by the Portuguese Association of Physiotherapists, and was provided to a total of 3,266 members (6.2\% response). As a result, the following data is not representative of the population.

The study included physiotherapists holding at least a Bachelor degree and working in manual therapy. Foreign physiotherapists were excluded. The questionnaire was available for filling from $23^{\text {rd }}$ March to 1st May 2015 (Appendix 1). 


\section{Instruments}

In order to assess the type of model used by physiotherapists who work in manual therapy, a questionnaire composed of two parts was used. The first part was an elaborated and validated questionnaire, and the second part, was the Physiotherapist Scale of Attitudes and Beliefs Scale (PABS-PT).

The first part of the questionnaire consists of an introductory text and a total of 23 questions, in which 5 questions were to characterize the sample, 3 questions about the knowledge of health models and 15 questions, about attitudes and behaviours of physiotherapists in the intervention.

The second part contains the PABS-PT scale. This scale was developed to evaluate attitudes and beliefs of physiotherapists, discriminating between a biomedical and biopsychosocial orientation [10]. The reliability value given by ICC (2.1) is 0,806 for biomedical factor and 0,653 for biopsychosocial factor $(\mathrm{p}=0.001)$ [48].

The scale used in this study consists of 36 items which were separated into two factors: factor 1 (biomedical) is composed of 10 items $(10,14,20,22,23,24,25,30,31$ and 35) and factor 2 (biopsychosocial) of 9 items $(6,7,11,12,17,27,29,33$ and 34) [49].

The score for each statement is made according to a six-point Likert scale, ranging from "totally disagree" (1 point) to "strongly agree" (6 points) $[10,49]$. In the end, the score's calculation is done by the addition of the answers corresponding to each subscale (biomedical and biopsychosocial). The minimum value of biomedical orientation was 10 and maximum 60 and the minimum value of biopsychosocial orientation were 9 and maximum 54. Higher scores on a subscale indicate a strong orientation to that model $[48,49,50-52]$.

\section{Procedures}

Construction of a questionnaire: The development of the questionnaire resulted from extensive bibliographical research, both on the subject under study and the methodology used. The questionnaire was designed to obtain the necessary information to answer the research question, but was first subjected to a pilot study, in order to test it, as well as to enable the researcher to handle and subsequent data analysis.

The construction of the questionnaire was an interactive process, which involved the analysis of a panel of four experts, who were also physiotherapists, with clinical experience and knowledge of the subject [53], who made comments, made changes to the original research and created a final version. These two steps give content validity to this questionnaire [53].

In order for the study to have inter-observer reliability, Portney \& Watkins (1993) recommend ICC (2.1), ICC being, the Intraclass Correlation Coefficient [54,55]. In order to measure the reliability of the questionnaire, it was applied in two different occasions, a week apart. The test-retest was applied to 10 physiotherapists who respected the inclusion and exclusion criteria (been excluded from the final sample). However, Crocker \& Algina (1986) and Pasquali (1999) report that 10 subjects are required for each item/ dimension evaluated to be considered as a sufficient sample in instrument evaluation studies, so in this study 180 individuals would be necessary (18 items/dimensions in the questionnaire) for the calculation of intra-observer reliability. However, because of time related issues, a reduced sample of a preliminary study of the reliability of the questionnaire was carried out [56,57].

With the ICC calculation (2.1) the value of 1 indicates perfect reliability. For values between 0.8 and 0.9 the reliability is considered good, between 0.7 and 0.8 the reliability is considered reasonable and for values lower than 0.7 the reliability is considered weak [58].

Implementation of the questionnaire to ascertain which health model best fits the clinical practice of physiotherapists who work with manual therapy: The Portuguese Physiotherapists Association was contacted through the use of electronic mail, after this they distributed the questionnaires via e-mail to its members. The questionnaire was available for online completion through the docs.google.platform.

\section{Ethic}

This study was evaluated and approved by the Ethics Committee of the School of Health Technology of Porto-IPP, with registration number 1594/2015 (Appendix 2). Through the introductory text of the questionnaire, the participants were previously clarified about the purpose and procedure of the study and were previously enlightened to the possibility of clarifying doubts through the contacts assigned to it. The confidentiality and anonymity of the data collected was ensured by naming the individuals who answered the questionnaire by the date and time of the answer.

\section{Statistics}

Calculation of the reliability of the questionnaire to ascertain which health model best fits the clinical practice of physiotherapists who work with manual therapy: For the validation of the questionnaire, the ICC (2.1) was calculated for the preliminary intra-observer reliability study. 
Application of questionnaire: A data analysis was performed using the IBM SPSS Statistics software (Statistical Package for Social Sciences), version 22, with a significance level of 0.05 and 95\% confidence level, and aided by Microsoft Excel 2010.

For the analysis of the questionnaire, the descriptive statistic was used to:

I. Characterize the sample;

II. Verify the time available for health education for the purpose of thought/behaviour change,

III. Verify the relationship between the health model choice and the scale result PABS-PT;

IV. Verify the relationship between the choice of the health model with the knowledge of other health models;

V. Verify the relationship between the choice of the health model and the importance directed to the resolution of the physical symptomatology/empathy effects between the user and the physiotherapist/importance to the environment/changes in the behaviour as well as components most work/give more importance by physiotherapists.

To see if there was an association between the choice of the health model and the characteristics of the individuals (gender, age, years of work and academic qualifications), the Chi-Square test was used. Spearman's Ordinal Correlation Coefficient (CCOS) was used to verify the correlation between the choice of health model, which is based on clinical practice, and the denomination used to refer to the person on whom the intervention was performed. This test was also used to verify the degree of correlation between the choice of the health model and the perception of the definition of the model.

In the analysis of the data, the characteristics of physiotherapists (years of work and age) were grouped into classes (Table 8). Table 6 shows the variables related to the degree of importance directed by physiotherapists to the components of clinical practice, which refer to the sum of attributed degrees of importance (values between 5 and 6).

\section{Results}

\section{Questionnaire's construction}

Table 1 shows the results of the preliminary reliability study that evaluates which health model best suits the clinical practice of physiotherapists working in manual therapy. The ICC values vary between 0.4 and 1 , so between weak and perfect reliability and only four items present values of 0.4 . In addition, $42.7 \%$ of the items have perfect reliability, $29.4 \%$ have good reliability, $2.7 \%$ have reasonable reliability and $25.3 \%$ have weak reliability. So, $72.1 \%$ of the items have a reliability which is greater than or equal to good.

\begin{tabular}{|c|c|c|c|c|c|c|c|c|c|c|c|}
\hline Question & ICC & Question & ICC & Question & ICC & Question & ICC & Question & ICC & Question & ICC \\
\hline $\mathbf{n r}$ & & $\mathbf{n r}$ & & $\mathbf{n r}$ & & $\mathbf{n r}$ & & $\mathbf{n r}$ & & $\mathbf{n r}$ & \\
\hline $\mathbf{6 . 1}$ & 1 & $\mathbf{9 . 3}$ & $\mathbf{1}$ & $\mathbf{1 1 . 5}$ & 0.4 & $\mathbf{1 4 . 2 . 2}$ & 0.8 & $\mathbf{1 7 . 1 . 1}$ & 1 & $\mathbf{2 0 . 4}$ & 0.8 \\
\hline $\mathbf{6 . 2}$ & 1 & $\mathbf{9 . 4}$ & 0.8 & $\mathbf{1 1 . 6}$ & 0.8 & $\mathbf{1 4 . 2 . 3}$ & 1 & $\mathbf{1 7 . 1 . 2}$ & 0.6 & $\mathbf{2 0 . 5}$ & 0.6 \\
\hline $\mathbf{6 . 3}$ & 1 & $\mathbf{9 . 5}$ & 1 & $\mathbf{1 1 . 7}$ & $\mathbf{0 . 6}$ & $\mathbf{1 4 . 2 . 4}$ & 1 & $\mathbf{1 7 . 1 . 3}$ & 0.6 & $\mathbf{2 0 . 6}$ & 0.8 \\
\hline $\mathbf{6 . 4}$ & 1 & $\mathbf{1 0 . 1}$ & 1 & $\mathbf{1 1 . 8}$ & 0.8 & $\mathbf{1 4 . 2 . 5}$ & 1 & $\mathbf{1 7 . 1 . 4}$ & 1 & $\mathbf{2 0 . 7}$ & 1 \\
\hline $\mathbf{7}$ & 1 & $\mathbf{1 0 . 2}$ & 0.8 & $\mathbf{1 1 . 9}$ & 1 & $\mathbf{1 4 . 2 . 6}$ & 1 & $\mathbf{1 7 . 1 . 5}$ & 1 & $\mathbf{2 0 . 8}$ & 1 \\
\hline $\mathbf{8 . 1}$ & 1 & $\mathbf{1 0 . 3}$ & 0.6 & $\mathbf{1 2}$ & 0.8 & $\mathbf{1 5}$ & 0.6 & $\mathbf{1 7 . 2 . 1}$ & 1 & $\mathbf{2 1 . 1}$ & 0.4 \\
\hline $\mathbf{8 . 2}$ & 0.8 & $\mathbf{1 0 . 4}$ & 0.8 & $\mathbf{1 3}$ & 0.8 & $\mathbf{1 6 . 1 . 1}$ & 0.6 & $\mathbf{1 7 . 2 . 2}$ & 1 & $\mathbf{2 1 . 2}$ & 0.6 \\
\hline $\mathbf{8 . 3}$ & 0.8 & $\mathbf{1 0 . 5}$ & 0.8 & $\mathbf{1 4 . 1 . 1}$ & 0.8 & $\mathbf{1 6 . 1 . 2}$ & 0.4 & $\mathbf{1 8}$ & 0.6 & $\mathbf{2 1 . 3}$ & 0.4 \\
\hline $\mathbf{8 . 4}$ & 0.8 & $\mathbf{1 0 . 6}$ & 0.6 & $\mathbf{1 4 . 1 . 2}$ & 1 & $\mathbf{1 6 . 1 . 3}$ & 0.6 & $\mathbf{1 9}$ & 0.8 & $\mathbf{2 1 . 4}$ & 0.6 \\
\hline $\mathbf{8 . 5}$ & 1 & $\mathbf{1 1 . 1}$ & 1 & $\mathbf{1 4 . 1 . 3}$ & 0.6 & $\mathbf{1 6 . 1 . 4}$ & 1 & $\mathbf{2 0 . 1}$ & 0.7 & $\mathbf{2 1 . 5}$ & 0.6 \\
\hline $\mathbf{9 . 1}$ & 0.8 & $\mathbf{1 1 . 2}$ & 1 & $\mathbf{1 4 . 1 . 4}$ & 0.8 & $\mathbf{1 6 . 1 . 5}$ & 1 & $\mathbf{2 0 . 2}$ & 0.9 & $\mathbf{2 1 . 6}$ & 0.6 \\
\hline $\mathbf{9 . 2}$ & 0.8 & $\mathbf{1 1 . 3}$ & 1 & $\mathbf{1 4 . 2 . 1}$ & 0.8 & $\mathbf{1 6 . 2 . 1}$ & 1 & $\mathbf{2 0 . 3}$ & 0.7 & $\mathbf{2 2}$ & 0.9 \\
\hline & & $\mathbf{1 1 . 4}$ & 1 & & & $\mathbf{1 6 . 2 . 2}$ & 1 & & & $\mathbf{2 3}$ & 1 \\
\hline
\end{tabular}

Table 1: Reliability questionnaire to assess manual therapists' health model based clinical practice

\section{Sample characteristics}

The sample is composed of 203 manual therapists, 122 (60.1\%) are females and $81(39.9 \%)$ are males with an average age of $29.64 \pm$ 8.014 years, with most responses in Porto and Lisbon (51.8\%). On average, the physiotherapists have about 7 years of professional experience.

\section{Health model based on the clinical practice of physiotherapists}

The holistic model and the biopsychosocial model are the models in which most physiotherapists fit their clinical practice, $42.4 \%$ and $41.9 \%$, respectively. The least-reported model was the ecological model (1.5\%) (Figure 1). 


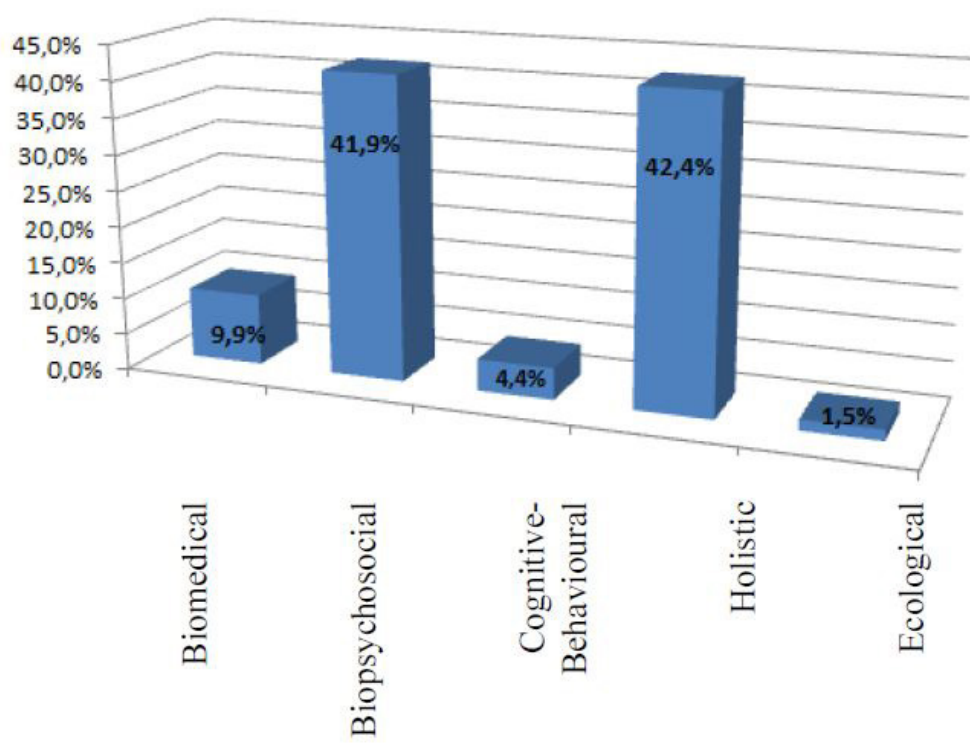

Figure 1: Therapists' health model based clinical practice

\section{Knowledge of health model shown by physiotherapists}

The holistic model and the biopsychosocial model are the most known models by physiotherapists, $76.4 \%$ and $73.9 \%$, respectively. The ecological model is the least known health model (Figure 2).

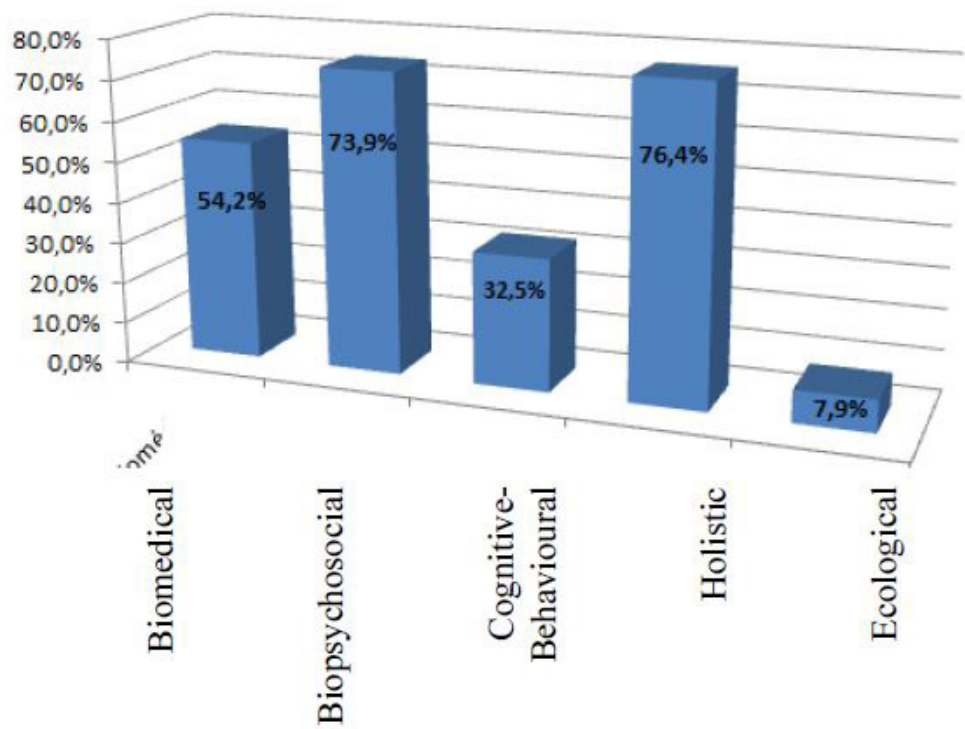

Figure 2: Knowledge of health model shown by physiotherapists

Note-These data were taken from question 8 of the questionnaire, where it was possible to select the health model

When the degree of concordance relatively to the physiotherapist's knowledge on other health models and the health model that serves as a basis for their clinical practice was evaluated, it was verified that those who work based on the ecological model have knowledge about all other models but, on the other hand, those who present more limited knowledge about the different health models are those who exert their practice based on the biomedical model. However, in general, despite the health model that underlies the clinical practice of physiotherapists, a high percentage of professionals are aware of other health models (Table 2).

\section{Analysis of attitudes and behavior of physiotherapists regarding their health model based clinical practice}

Designation used by physiotherapists to refer to the person on whom the intervention has been carried out, relatively to the health model based clinical practice: As can be seen in Table 3, there were significant differences between the designation used by physiotherapists and the health model that they based their own clinical practice.Those that base their clinical practice on the biomedical and holistic model predominately refer to the person as a 'patient' whereas those that use the biopsychosocial and cognitive-behavioral model refer to them as 'user'. A greater number of physiotherapists use a designation of 'user' instead to the 
term 'patient', which is less used.

\begin{tabular}{|c|c|c|c|c|c|}
\hline & \multicolumn{3}{|c|}{ Health model that fits into the clinical practice of physiotherapist manual therapy } \\
\hline $\begin{array}{c}\text { Knowledge of health } \\
\text { model shown by physi- } \\
\text { otherapists }\end{array}$ & $\begin{array}{c}\text { Biomedical } \\
(\mathbf{n}=\mathbf{2 0})\end{array}$ & $\begin{array}{c}\text { Biopsychosocial } \\
(\mathbf{n = 8 3 )}\end{array}$ & $\begin{array}{c}\text { Cognitive-Behavioural } \\
(\mathbf{n = 9})\end{array}$ & $\begin{array}{c}\text { Holistic } \\
(\mathbf{n}=\mathbf{8 9})\end{array}$ & $\begin{array}{c}\text { Ecological } \\
(\mathbf{n}=\mathbf{3})\end{array}$ \\
\hline Biomedical & $5 \%$ & $60 \%$ & $44.4 \%$ & $38.4 \%$ & $\mathbf{1 0 0 \%}$ \\
\hline Biopsychosocial & $50 \%$ & $95.3 \%$ & $88.9 \%$ & $55.8 \%$ & $\mathbf{1 0 0 \%}$ \\
\hline Cognitive-Behavioural & $20 \%$ & $31.8 \%$ & $88.9 \%$ & $27.9 \%$ & $\mathbf{1 0 0 \%}$ \\
\hline Holistic & $65 \%$ & $52.9 \%$ & $88.9 \%$ & $100 \%$ & $\mathbf{1 0 0 \%}$ \\
\hline Ecological & $5 \%$ & $7.1 \%$ & $22.2 \%$ & $4.7 \%$ & $\mathbf{1 0 0 \%}$ \\
\hline
\end{tabular}

Table 2: Knowledge of other health models related to health model based clinical practice

\begin{tabular}{|c|c|c|c|c|c|c|}
\hline & \multicolumn{6}{|c|}{ Health model that fits into the clinical practice of physiotherapists who work in manual therapy } \\
\hline Patient & $35 \%$ & $30.6 \%$ & $33.3 \%$ & $40.7 \%$ & $33.3 \%$ & 0.021 \\
\hline
\end{tabular}

Table 3: Designation used by physiotherapists in relation to health model

Components assessed by physiotherapists' related to health model based clinical practice: The evaluation components most frequently mentioned by physiotherapists in the different health models are physical symptoms, clinical history and cause of the pathology. However, the physiotherapists that selected the cognitive-behavioral and ecological model also give high relevance to the psychological and behavioral component (Table 4).

\begin{tabular}{|c|c|c|c|c|c|}
\hline \multirow[b]{2}{*}{ Components assessed } & \multicolumn{5}{|c|}{ Health model that fits into the clinical practice of physiotherapists who work in manual therapy } \\
\hline & $\begin{array}{l}\text { Biomedical } \\
\quad(n=20)\end{array}$ & $\begin{array}{l}\text { Biopsychosocial } \\
\qquad(n=83)\end{array}$ & $\begin{array}{c}\text { Cognitive-Behavioral } \\
\qquad(\mathrm{n}=9)\end{array}$ & $\begin{array}{c}\text { Holistic } \\
(n=89)\end{array}$ & $\begin{array}{l}\text { Ecological } \\
\qquad(n=3)\end{array}$ \\
\hline Physical symptoms & $100 \%$ & $97.6 \%$ & $100 \%$ & $97.7 \%$ & $100 \%$ \\
\hline Clinical History & $90 \%$ & $94.1 \%$ & $100 \%$ & $96.5 \%$ & $100 \%$ \\
\hline Pathology cause & $85 \%$ & $78.8 \%$ & $88.9 \%$ & $87.2 \%$ & $100 \%$ \\
\hline Emotional condition & $40 \%$ & $58.8 \%$ & $88.9 \%$ & $58.1 \%$ & $100 \%$ \\
\hline Family condition & $25 \%$ & $35.3 \%$ & $66.7 \%$ & $33.7 \%$ & $66.7 \%$ \\
\hline Surrounding environment & $45 \%$ & $52.9 \%$ & $66.7 \%$ & $54.7 \%$ & $66.7 \%$ \\
\hline Social situation & $20 \%$ & $45.9 \%$ & $55.6 \%$ & $47.7 \%$ & $66.7 \%$ \\
\hline Psychological condition & $40 \%$ & $65.9 \%$ & $100 \%$ & $73.3 \%$ & $100 \%$ \\
\hline Behavior & $55 \%$ & $71.8 \%$ & $88.9 \%$ & $79.1 \%$ & $100 \%$ \\
\hline
\end{tabular}

Table 5 shows that, generally, physiotherapists give high importance to the resolution of physical symptoms, with higher incidence on physiotherapists that considered the basis model for clinical practice, the biomedical and biopsychosocial model.

\begin{tabular}{|c|c|c|c|c|c|}
\hline & \multicolumn{5}{|c|}{ Health model that fits into the clinical practice of physiotherapistswho work in manual therapy } \\
\hline & $\begin{array}{l}\text { Biomedical } \\
\quad(n=20)\end{array}$ & $\begin{array}{l}\text { Biopsychosocial } \\
\quad(n=83)\end{array}$ & $\begin{array}{l}\text { Cognitive-Behavioral } \\
(\mathbf{n}=9)\end{array}$ & $\begin{array}{l}\text { Holistic } \\
(\mathrm{n}=89)\end{array}$ & $\begin{array}{l}\text { Ecological } \\
\quad(n=3)\end{array}$ \\
\hline $\begin{array}{c}\text { Too much or extreme importance given to } \\
\text { solving symptoms }\end{array}$ & $90 \%$ & $94.2 \%$ & $55.5 \%$ & $87.2 \%$ & $66.6 \%$ \\
\hline $\begin{array}{l}\text { Some or a high level of empathy between the } \\
\text { user and physiotherapist at intervention }\end{array}$ & $85 \%$ & $95.3 \%$ & $100 \%$ & $96.5 \%$ & $100 \%$ \\
\hline $\begin{array}{l}\text { Too much or extreme importance given to } \\
\text { the surrounding environment }\end{array}$ & $30 \%$ & $48.3 \%$ & $55.5 \%$ & $50 \%$ & $33.3 \%$ \\
\hline $\begin{array}{l}\text { Some or a high attention given to users' } \\
\text { behavioral changes }\end{array}$ & $85 \%$ & $84.7 \%$ & $100 \%$ & $88.3 \%$ & $100 \%$ \\
\hline
\end{tabular}

Table 5: Physiotherapist's attitude and behavioual analysis related to health model 
A large number of physiotherapists, whatever the choice of model, refer that empathy has some or a big effect during an intervention. Despite the little relevance, physiotherapists that base the intervention in the biomedical model refer lower effects of empathy in intervention.

The physiotherapists who selected the ecological model, 33.3\% considered the environment important. However, only 3 physiotherapists of the sample selected the ecological model option.

More than $85 \%$ of physiotherapists, regardless of the model choice, refer giving some or a lot of attention to change in behavior.

Regarding the time spent by a physiotherapist in health education, it was verified that $11.8 \%$ of physiotherapists don't spend any time on it, as $48.3 \%$ reported to spend neither too much nor too little time on health education to accomplish behaviour change/ thought.

Relationship between the components physiotherapists give more importance to or work more and the health model they base their clinical practice on: Physiotherapists give more importance to and work more with biological and physical components, with the exception of the cognitive-behavioral and ecological models, thus increasing the importance/intervention in the psychological and behavioral component (Table 6). The results show a concordance between the components which are focused on the most and which areas are given more importance.

\begin{tabular}{|c|c|c|c|c|c|c|c|c|c|c|}
\hline \multirow[b]{3}{*}{$\begin{array}{l}\text { Physiotherapists most impor- } \\
\text { tant and working components }\end{array}$} & \multicolumn{10}{|c|}{ Health model that fits into the clinical practice of physiotherapistswho work in manual therapy } \\
\hline & \multicolumn{2}{|c|}{ Biomedical $(n=20)$} & \multicolumn{2}{|c|}{$\begin{array}{l}\text { Biopsychosocial } \\
\quad(n=83)\end{array}$} & \multicolumn{2}{|c|}{$\begin{array}{l}\text { Cognitive-Behavioral } \\
\qquad(\mathrm{n}=9)\end{array}$} & \multicolumn{2}{|c|}{$\begin{array}{c}\text { Holistic } \\
(\mathrm{n}=89)\end{array}$} & \multicolumn{2}{|c|}{$\begin{array}{l}\text { Ecological } \\
\quad(\mathrm{n}=3)\end{array}$} \\
\hline & I & W & I & $\mathrm{W}$ & I & $\mathrm{W}$ & I & W & I & W \\
\hline Biological component & $80 \%$ & $75 \%$ & $72.9 \%$ & $83.5 \%$ & $66.6 \%$ & $77.8 \%$ & $81.4 \%$ & $87.2 \%$ & $66.7 \%$ & $33.3 \%$ \\
\hline Physical component & $95 \%$ & $90 \%$ & $84.7 \%$ & $83.5 \%$ & $44.4 \%$ & $88.9 \%$ & $73.3 \%$ & $82.6 \%$ & $100 \%$ & $100 \%$ \\
\hline Social component & $10 \%$ & $15 \%$ & $31.8 \%$ & $28.2 \%$ & $0 \%$ & $44.4 \%$ & $24.4 \%$ & $29.1 \%$ & $0 \%$ & $0 \%$ \\
\hline Environmental component & $10 \%$ & $5 \%$ & $28.2 \%$ & $23.5 \%$ & $11.1 \%$ & $33.3 \%$ & $20.9 \%$ & $18.6 \%$ & $0 \%$ & $0 \%$ \\
\hline Psychological component & $10 \%$ & $25 \%$ & $56.5 \%$ & $55.3 \%$ & $77.8 \%$ & $66.7 \%$ & $51.2 \%$ & $62.8 \%$ & $0 \%$ & $66.7 \%$ \\
\hline Behavioral component & $25 \%$ & $40 \%$ & $51.8 \%$ & $62.4 \%$ & $66.6 \%$ & $55.6 \%$ & $57 \%$ & $52.3 \%$ & $0 \%$ & $33.3 \%$ \\
\hline
\end{tabular}

Table 6: Relationship between the components physiotherapists give more importance to or work more and the health model they base their clinical practice on Health model that fits into the clinical practice of physiotherapistswho work in manual therapy

\section{Correlation between perceived and real health models on which physiotherapists base their clinical practice}

There are no statistically significant differences between the perceived model and real health model which physiotherapists use in their clinical practice. Table 7 shows that most physiotherapists have a perception that their clinical practice is based on the holistic and the biopsychosocial models. Only 1.5\% stated that it was based on the ecological model. After having access to the model's definitions, most maintained the answer with small changes. The degree of concordance decreases for the physiotherapists who had selected the biomedical and biopsychosocial model, changing the selection for the holistic model, however these differences are not significant.

\begin{tabular}{|c|c|c|c|}
\hline & $\begin{array}{c}\text { Model's choice without seeing } \\
\text { the definition - n (\%) }\end{array}$ & $\begin{array}{c}\text { Model choice consulting defini- } \\
\text { tion - n (\%) }\end{array}$ & Difference between answers \\
\hline Biomedical & $20(9.9 \%)$ & $13(6.4 \%)$ & $-3.5 \%$ \\
\hline Biopsychosocial & $85(41.9 \%)$ & $78(38.4 \%)$ & $-3.5 \%$ \\
\hline Cognitive-Behavioral & $9(4.4 \%)$ & $9(4.4 \%)$ & 0.802 \\
\hline Holistic & $86(42.4 \%)$ & $100(49.3 \%)$ & $+6.9 \%$ \\
\hline Ecological & $3(1.5 \%)$ & $3(1.5 \%)$ & $0 \%$ \\
\hline
\end{tabular}

Table 7: Agreement between perceived and real health model on which physiotherapists base their clinical practice

\section{Physiotherapists' attitudes and beliefs analysis regarding the health model they base their clinical practice on}

When analyzing the attitudes and beliefs of physiotherapists through the PABS-PT scale, 9.85\% demonstrated a biomedical orientation and $41.87 \%$ showed a biopsychosocial orientation.

Comparing the choice of health model in the questionnaire and analysis of attitudes and beliefs of physiotherapists, it was observed that of the 85 physiotherapists who chose a biopsychosocial model, only 33 physiotherapists (38.8\%) on the PABS-PT scale obtained the same orientation. On the other hand, of the 20 physiotherapists who chose the biomedical model, 16 physiotherapists $(80 \%)$ had the same option in PABS-PT scale. 


\section{Physiotherapists' profile related to health model}

The profile of physiotherapists, including age, gender, years of work experience and academic qualifications are independent of the choice of health model used (Table 8).

\begin{tabular}{|c|c|c|c|c|c|c|c|}
\hline & \multicolumn{7}{|c|}{ Health model that fits into the clinical practice of physiotherapists who work in manual therapy } \\
\hline & & $\begin{array}{l}\text { Biomedical } \\
\quad(n=20)\end{array}$ & $\begin{array}{c}\text { Biopsychosocial } \\
(n=83)\end{array}$ & $\begin{array}{c}\text { Cognitive-Behavioral } \\
\qquad(\mathrm{n}=9)\end{array}$ & $\begin{array}{c}\text { Holistic } \\
(n=89)\end{array}$ & $\begin{array}{l}\text { Ecological } \\
\qquad(n=3)\end{array}$ & $\mathbf{p}$ \\
\hline \multirow{2}{*}{ Age } & [20-40 years] & $9.8 \%$ & $42.9 \%$ & $4.9 \%$ & $41.3 \%$ & $1.1 \%$ & \multirow{2}{*}{0.403} \\
\hline & More than 40 years & $10.5 \%$ & $31.6 \%$ & $0 \%$ & $52.6 \%$ & $5.3 \%$ & \\
\hline \multirow{2}{*}{$\begin{array}{l}\text { Working } \\
\text { years }\end{array}$} & Less than 15 years & $10.4 \%$ & $42.1 \%$ & $4.4 \%$ & $42.1 \%$ & $1 \%$ & \multirow{2}{*}{0.651} \\
\hline & 16 or more years & $5 \%$ & $40 \%$ & $5 \%$ & $45 \%$ & $5 \%$ & \\
\hline \multirow{2}{*}{ Gender } & Female & $8.2 \%$ & $45.9 \%$ & $4.9 \%$ & $39.4 \%$ & $1.6 \%$ & \multirow{2}{*}{0.573} \\
\hline & Male & $12.3 \%$ & $35.9 \%$ & $3.7 \%$ & $46.9 \%$ & $1.2 \%$ & \\
\hline \multirow{3}{*}{$\begin{array}{c}\text { Academic } \\
\text { qualifications }\end{array}$} & $\begin{array}{l}\text { Bachelor Degree } \\
\qquad(n=162)\end{array}$ & $9.9 \%$ & $41.9 \%$ & $4.7 \%$ & $42.3 \%$ & $1.2 \%$ & \multirow{3}{*}{0.853} \\
\hline & Master degree $(n=10)$ & $0 \%$ & $44.4 \%$ & $0 \%$ & $55.6 \%$ & $0 \%$ & \\
\hline & Postgraduate $(\mathrm{n}=31)$ & $9.7 \%$ & $41.9 \%$ & $3.3 \%$ & $41.9 \%$ & $3.2 \%$ & \\
\hline
\end{tabular}

\section{Discussion}

In this study, it was verified that most responders chose the holistic model. However, when verifying the results, we found that the intervention, they perform didn't match the model. They focus more on the biological and physical components, with occasional exceptions to physiotherapists who chose the ecological and cognitive-behavioural model, which give more attention to the psychological and behavioural components. Although physiotherapists change their thinking and apply a holistic view, most had training based on the biomedical model [10]. The diversity of physiotherapy allows an approaching of pathologies with different perspectives and in a cohesive way, since the main objective is to treat the individual as a whole and not only physical symptoms [59].

In relation to knowledge of health models, the holistic and biopsychosocial models are the best known ones, in contrast to the ecological model. From the physiotherapists who selected the biomedical model, the majority know the biopsychosocial and the holistic models, and are aware of their own model of action. Although they also recognize other broader health models, they prioritize physical issues [21]. Moreover, the results confirmed that the 3 physiotherapists who base their clinical practice on the ecological model know all the models, with is in keeping with [44], who states that it is the most recent model and encompasses all previous ones.

Regarding attitudes and behaviors during the intervention, several aspects were analyzed. The term used to designate a person who receives an intervention is not directly related to the health model that the clinical practice is based on, contrary to what [60] who argue that physiotherapists who use the biomedical model have a tendency to call the person by the oldest and most conventional term: a 'patient/sick', since both refer to a pathology based intervention and do not take into account other components. In this way, the person is considered passive and without opinion about the intervation. The term 'client' and 'user' are most used by physiotherapists who do the intervention with more global models, in which the person has the right of decision and opinion about the intervention. Saito, et al, (2013) also mention that the term 'user' is a more appropriate designation, since it includes the term 'patient' and 'client' simultaneously [60].

The results further indicated that during evaluation the greatest attention is given to physical symptoms, clinical history and the cause of the pathology. So, even in universities that introduce broader health models as the basis for their training programs, most of the time and attention is channeled into the biomedical assessment and resolution of physical symptoms [22]. Evaluation therefore becomes a necessary basis to prioritize the main problems of the user when collecting their medical history [61].

Of the physiotherapists who have chosen the biomedical model, 90\% stated that the resolution of physical symptoms was very important or extremely important. The other models, despite their broader approach, also directed a high percentage to resolution of physical symptoms. According to [21], physiotherapists establish their own limits in clinical practice, allowing them to act within the confidence zone, with a greater focus on physical components.

Of the physiotherapists who chose the ecological model, $33.3 \%$ stated that the environment that surrounds the user is extremely important. The remaining individuals who chose the other models give little or no importance to the environment. These data are justified by [43], who affirms that the ecological model represents a health promotion strategy, including changes in the community. For these models that refer the environment as little or not important at all, the environment is not a necessary component in intervention based on these health models. 
Most physiotherapists reported as very important or extremely important the behavioural changes resulting from the pathology. However, $8.6 \%$ of physiotherapists (using the biomedical, biopsychosocial and holistic models) report behavioral changes as less important or unimportant. These results also confirm other results obtained in the questionnaire, in which most physiotherapists give little time to health education for the purpose of behavioral/thinking changes and, according to [12], health education, together with the intervention, has better physical and psychological results. For many physiotherapists, the behavior of the user has become an important outcome of treatment [17]. If the physiotherapist has difficulties in understanding the behavior of the user, advise specific training to try changing the situation [17].

Regarding the effects of empathy between the user and physiotherapist during the intervention, it can be seen that a large number of physiotherapists, regardless of the model choice, indicate that empathy is very important or extremely important. Although not very relevant, the physiotherapists who base their clinical practice on the biomedical model demonstrated a lower percentage than the other models and was the only model in which they chose the option with little or no effect. According to Parker, et al. (2014), in clinical practice based on the biomedical model, people are being treated as objects [62]. In broader interventions, the user should be treated with empathy and comprehension [63]. Physiotherapists recognize the negative impact of language or attitude during the intervention and refer the need to ensure that users interpret the clinical message correctly. Good communication and the creation of a connection between the user and physiotherapist is an added value in the intervention [21]. As reported by [64], physiotherapists obtain information about psychosocial issues informally, during conversations with the user, because the professionals fear that users feel that they are intruding in their private life. Because of this, some physiotherapists report that working with psychosocial issues is the responsibility of psychologists and social workers [64]. However, there is a growing interest in doing this type of intervention by the physiotherapist, due to the great contact with the user and because these aspects could be related to physical causes [65]. If physiotherapists cannot provide this support, the possibility of it taking place concurrently with the physiotherapy should be considered [64]. The alternative would be to provide the physiotherapist with specialized training [19].

Physiotherapists were questioned about the components that work the best and the components that are given more importance, where biological and physical components (the basis of the biomedical model) were selected, with the exception of physiotherapists who selected the ecological and cognitive-behavioral models, who refer working more with the psychological and behavioral components. The social, psychological and environmental components, although emphasized by some physiotherapists who selected the mentioned models, are the least worked. It's expected that physiotherapy evaluates and acts on all components, however, physiotherapists neglect some psychosocial aspects of the user, even though they know the relevance of emotional and social needs [64]. According to Barros (2002), this happens because physiotherapists, despite admitting the influence of psychosocial components, do not feel comfortable dealing with them, due to lack of preparation [14,66]. They also refer to a lack of knowledge/training and experience, denying responsibility $[19,21,64,66]$. Some authors report that the results of broader intervention are variable, due to the limitations/non-existence of instruments to measure psychosocial components, and are not comparable or reliable [21,67].

When analyzing the correlation between the health model that serves as a basis for clinical practice and the attitudes and beliefs of physiotherapists, the findings showed that the physiotherapists working with the biomedical model are more aware of their own health model, contrary to the physiotherapists who use the biopsychosocial model. Less than half of the physiotherapists, in the PABS-PT scale, obtained the same orientation. These data are in agreement with Nijs, et al. (2013), who report that physiotherapists, despite referring to intervening more broadly, continue to focus mainly on the physical components [10].

This inconsistency may be because the instruments are different, therefore producing different results. In this case, the PABS-PT scale showed a higher percentage of individuals with a biopsychosocial orientation, whereas the analysis of the data in the first part of the questionnaire showedan intervention focused on the biomedical model.

The profile of physiotherapists, including factors such as age, gender, years of work and academic qualifications, showed that these characteristics are independent of the health model that is the basis for clinical practice. These data contrast with Domenech, et al., (2011), who states that the basis health model for clinical practice differs among physiotherapists, depending on academic training and age. Foster \& Delitto (2011) refer that physiotherapists with more years of work experience use the biomedical model, which is the oldest and most taught model in higher education. Some authors defend the change of program content at university, but didn't present another specific health model solution [27]. Domenech, et al., (2011) states that basing teaching on a broader model leads to more significant changes in clinical practice and earlier in professional life [27]. Foster \& Delitto (2011) report that it's possible to modify the intervention model of physiotherapists who already work, however, sustaining expressive changes is more difficult [22]. This is because the basic model for the intervention is not intentionally learned, but secondarily reinforced or suppressed, depending on the academic background [66]. A sample of physiotherapists with few years of work experience is expected to follow the holistic and/or ecological model, however, it may lead physiotherapists to attach importance to all components without actually knowing the purpose of the intervention.

The lack of information about the place/context of the intervention (hospital, conventional clinic, private office, among others), the school training, if they have access to all health model intervention and what health model supported the academic formation are the limitations of the present study that may be overcome in next ones. Although the sample was large $(n=203)$, separating 
the physiotherapists according to the health model they use in clinical practice, 3 of the 5 models were selected by less than 30 physiotherapists. In terms of population representativity, due to the low percentage of physiotherapists who responded, it is not possible to generalize these results on a national level. Regarding the results, this study may have been conditioned by the type of study and especially by the instrument used, and the results may indicate social desirability, since the attitudes and behaviors indicate a biomedical orientation while the perception of the model on which clinical practice is based tends to focus on broader health models [67-71].

This work is important for physiotherapy because it's a contribution to the awareness of the physiotherapist models in clinical practice, facilitating the perception and differentiation of the types of intervention, due to the different health models. Further investigations are necessary in order to determine the reality of Portuguese physiotherapists. It's also recommended that universities standardize program content in a more broader (holistic and / or ecological) health models, as well as in workplaces, it's recommended an improvement of working conditions in order to facilitate the intervention of physiotherapists in all components of the individual.

\section{Conclusion}

Physiotherapists' who work in manual therapy believe that the holistic model is the health model on which to base clinical practice. However, attitudes and behaviors in intervention and evaluation remain focused on the biomedical model towards the resolution of physical symptoms.

The best-known health models are the holistic and biopsychosocial, as opposed to the ecological model.

After having seen the health models definition, physiotherapists emphasized the choice in the holistic model.

Physiotherapists' profile is independent of health model based clinical practice. Physiotherapists' who base their practice on the biomedical model are more aware of their own health model.

\section{Supplementary}

\section{References}

1. WCPT (2015) What is physical therapy, London, UK.

2. APFISIO (2015) The Portuguese Association of Physiotherapists, Portugal.

3. Espíndola DS, Borenstein MS (2011) The historical evolution of physical therapy: from massage to professional recognition (1894-2010). Fisioter Bras 12: 389-94.

4. IFOMPT (2014) International Federation of Orthopaedic Manipulative Physical Therapists, Auckland New Zealand.

5. IFOMPT (2010) International Federation of Orthopaedic Manipulative Physical Therapists, Auckland New Zealand.

6. Reis J (2005) What is Health. Personal Significations, Scientific Models and Health Education. Ana Psychologica 23: n.2.

7. Blumer H (1986) Symbolic interactionism: Perspective and method, New Jersey, USA.

8. Lancet T (2009) What is health? The ability to adapt. Lancet 373: 781.

9. Sampaio RF, Mancini MC, Gonçalves GG, Bittencourt NF, Miranda AD, et al. (2005) Aplicação da classificação internacional de funcionalidade, incapacidade e saúde (CIF) na prática clínica do fisioterapeuta. Rev Bras Fisioter 9: 129-36.

10. Nijs J, Roussel N, Paul van Wilgen C, Köke A, Smeets R (2013) Thinking beyond muscles and joints: therapists' and patients' attitudes and beliefs regarding chronic musculoskeletal pain are key to applying effective treatment. Manual therapy 18: 96-102.

11. Lundström LG (2008) Further arguments in support of a social humanistic perspective in physiotherapy versus the biomedical model. Physiother Theory Pract 24: 393-6.

12. Grimmer-Somers K, Milanese S, Kumar S (2012) Measuring the quality of allied health services in Australia: is it a case of the 'more we learn, the less we know. J Healthc Leadersh 4: 71-81.

13. Pereira MG (1995) Epidemiologia-Teoria e prática. Rio de Janeiro, São Paulo, Brazil.

14. Barros JAC (2002) considering the health-diesease process: what does the biomedical model answer to? Health soc11: 67-84.

15. Deacon BJ (2013) The biomedical model of mental disorder: A critical analysis of its validity, utility, and effects on psychotherapy research. Clin Psychol Rev 33: 846-61.

16. Borrett DS (2013) Heidegger, Gestell and rehabilitation of the biomedical model. J Eval Clin Pract 19: 497-500.

17. van Wilgen P, Beetsma A, Neels H, Roussel N, Nijs J (2014) Physical therapists should integrate illness perceptions in their assessment in patients with chronic musculoskeletal pain; a qualitative analysis. Man Ther 19: 229-34.

18. Toye F, Barker K (2010) 'Could I be imagining this?'-the dialectic struggles of people with persistent unexplained back pain. Disabil Rehabil 32 : $1722-32$.

19. Nielsen M, Keefe FJ, Bennell K, Jull GA (2014) Physical Therapist-Delivered Cognitive-Behavioral Therapy: A Qualitative Study of Physical Therapists' Perceptions and Experiences. Phys Ther 94: 197-209.

20. Campos MO, Rodrigues Neto JF (2014) Qualidade de vida: um instrumento para promoção de saúde. Revista Baiana de saúde pública 32: 232.

21. Sanders T, Foster NE, Bishop A, Ong BN (2013) Biopsychosocial care and the physiotherapy encounter: physiotherapists' accounts of back pain consultations. BMC musculoskeletal disord 14: 65 .

22. Foster, NE, Delitto A (2011) Embedding psychosocial perspectives within clínical management of low back pain: integration of psychosocially informed management principles into physical therapist practice-challenges and opportunities. Phys ther 91: 790-803.

23. Cederbom S, Rydwik E, Söderlund A, Denison E, Frändin K, et al. (2014) A behavioral medicine intervention for older women living alone with chronic pain-a feasibility study. Clin Interv Aging 9: 1383-97.

24. Alonso Y (2004) The biopsychosocial model in medical research: the evolution of the health concept over the last two decades. Patient Educ Couns 53: 239-44. 
25. Schwinges-Lymberopoulos M (2010) Psychosomatische Urologie. Der Urologe 49: 767-74.

26. Sveinsdottir V, Eriksen HR, Reme SE (2012) Assessing the role of cognitive behavioral therapy in the management of chronic nonspecific back pain. J Pain Res 5: 371-80.

27. Andrade JTD, Costa LFAD (2010) Complementary medicine in the SUS: integrative practices in the perspective of medical Anthropology. Health Soc 19: 497508 .

28. Hatchard T, Lepage C, Hutton B, Skidmore B, Poulin PA (2014) Comparative evaluation of group-based mindfulness-based stress reduction and cognitive behavioral therapy for the treatment and management of chronic pain disorders: protocol for a systematic review and meta-analysis with indirect comparisons. Syst Rev 3: 134.

29. Khan M, Akhter S, Soomro RR, Ali SS (2014) The effectiveness of Cognitive Behavioral Therapy (CBT) with general exercises versus general exercises alone in the management of chronic low back pain. Pak J Pharm Sci, 27: 1113-6.

30. Hansen Z, Daykin A, Lamb SE (2010) A cognitive-behavioural programme for the management of low back pain in primary care: a description and justification of the intervention used in the Back Skills Training Trial (BeST; ISRCTN 54717854). Physiotherapy 96: 87-94.

31. Wellington J (2014) Noninvasive and Alternative Management of Chronic Low Back Pain (Efficacy and Outcomes). Neuromodulation 17: 24-30.

32. Berg GV, Sarvimäki A (2003) A holistic-existential approach to health promotion. Scand J Caring Sci 17: 384-91.

33. Wade D (2011) Complexity, case-mix and rehabilitation: the importance of a holistic model of illness. Clin Rehabil 25: 387-95.

34. Polsgrove MJ (2012) A holistic approach to movement education in sport and fitness: A systems based model. J Bodyw Mov Ther 16: 36-41.

35. Separavich MA, Canesqui AM (2010) Girando a lente socioantropológica sobre o corpo: uma breve reflexão. Saúde e Sociedade 19: 249-59.

36. Fortune LD, Hymel GM (2015) Creating integrative work: A qualitative study of how massage therapists work with existing clients. J Bodyw Mov Ther 19: 25-34.

37. Supranowicz P, Paź M (2014) Holistic measurement of well-being: psychometric properties of the physical, mental and social well-being scale (PMSW-21) for adults. Rocz Panstw Zakl Hig 65: 251-8.

38. Somasundaram D (2007) Collective trauma in northern Sri Lanka: a qualitative psychosocial-ecological study. Int J Ment Health Syst 1: 5.

39. Sallis JF, Cervero RB, Ascher W, Henderson KA, Kraft MK, et al. (2006) An ecological approach to creating active living communities. Annu Rev Public Health 27: $297-322$.

40. Resnick B, Orwig D, D’Adamo C, Yu-Yahiro J, Hawkes W, et al. (2007) Factors that influence exercise activity among women post hip fracture participating in the Exercise Plus Program. Clin Interv Aging 2: 413-27.

41. Baral S, Logie CH, Grosso A, Wirtz AL, Beyrer C (2013) Modified social ecological model: a tool to guide the assessment of the risks and risk contexts of HIV epidemics. BMC Public Health 13: 482.

42. Stubbs B, Eggermont L, Soundy A, Probst M, Vandenbulcke M, et al. (2014) What are the factors associated with physical activity (PA) participation in community dwelling adults with dementia? Arch Gerontol Geriatr 59: 195-203.

43. Lohrmann DK (2010) A complementary ecological model of the coordinated school health program. Public Health Rep 80: 1-9.

44. Haas EJ, Hoebbel CL, Rost KA (2014) An Analysis of Trainers' Perspectives within an Ecological Framework: Factors that Influence Mine Safety Training Processes. Safety and health at work 5: 118-124.

45. Taylor A, Servage L (2012) Perpetuating education-jobs mismatch in a high school internship programme: an ecological model. J Edu Work 25: 163-83.

46. Mehtälä MAK, Sääkslahti AK, Inkinen ME, Poskiparta MEH (2014) A socio-ecological approach to physical activity interventions in childcare: a systematic review. International J Beha Nutr Phy Act 11: 22.

47. Hoover CR, Wong CC, Azzam A (2012) From primary care to public health: using problem-based learning and the ecological model to teach public health to first year medical students. J Community Health 37: 647-52.

48. Bowey-Morris J, Purcell-Jones G, Watson PJ (2010) Test-retest reliability of the pain attitudes and beliefs scale and sensitivity to change in a general practitioner population. Clin J Pain 26: 144-52.

49. Houben RM, Ostelo RW, Vlaeyen JW, Wolters PM, Peters M, et al. (2005) Health care providers' orientations towards common low back pain predict perceived harmfulness of physical activities and recommendations regarding return to normal activity. Eur J Pain 9: 173-83.

50. Bishop A, Thomas E, Foster NE (2007) Health care practitioners' attitudes and beliefs about low back pain: a systematic search and critical review of available measurement tools. Pain 132: 91-101.

51. LE Laekeman MA, Sitter H, Basler HD (2008) The Pain Attitudes and Beliefs Scale for Physiotherapists: psychometric properties of the German version. Clin Rehabil. 22: 564-75.

52. Ostelo RW, Stomp-van den Berg SG, Vlaeyen JW, Wolters PM, de Vet HC (2003) Health care provider's attitudes and beliefs towards chronic low back pain: the development of a questionnaire. Man Ther 8: 214-22.

53. Alexandre NM, Coluci MZ (2011) Content validity in the development and adaptation processes of measurement instruments. Cien Saude Colet 16: 3061-8.

54. Portney LG, Watkins MP (1993) Foundations of clínical research: applications to practice. Norwalk: Appleton \& Lange.

55. Bartko JJ (1966) The intraclass correlation coefficient as a measure of reliability. Psychol Rep 19: 3-11.

56. Crocker L, Algina J (1986) Introduction to classical and modern test theory. Wadsworth Publishing, New York.

57. Pasquali L (1999) Instrumentos psicológicos: manual prático de elaboração. LabPAM/IBAPP, Brasília, Brazil.

58. Peterson RA (1994) A meta-analysis of Cronbach's coefficient alpha. J Cons Res 2: 381-91.

59. CliftonSmith T, Rowley J (2011) Breathing pattern disorders and physiotherapy: inspiration for our profession. Phys Therapy Rev 16: 75-86.

60. Saito DYT, Zoboli ELCP, Schveitzer MC, Maeda ST (2013) User, client or patient?: which term is more frequently used by nursing students?. Texto ContextoEnfer 22: 175-83.

61. Nagarajan M, Nair MR (2010) Importance of fear-avoidance behavior in chronic non-specific low back pain. J Back Musculoskelet Rehabil 23: 87-95.

62. Parker S, Khatri R, Cook IG, Pant B (2014) Theorizing Aging in Nepal: Beyond the Biomedical Model. Can J Sociol 39: 231-54.

63. Stewart J, Kempenaar L, Lauchlan D (2011) Rethinking yellow flags. Man Ther 16: 196-8.

64. Portillo MC, Cowley S (2011) Working the way up in neurological rehabilitation: the holistic approach of nursing care. J Clin Nurs 20: 1731-43. 
65. Keefe FJ, Porter L, Somers T, Shelby R, Wren AV (2013) Psychosocial interventions for managing pain in older adults: outcomes and clínical implications. Br J Anaesth 111: 89-94.

66. Domenech J, Sánchez-Zuriaga D, Segura-Ortí E, Espejo-Tort B, Lisón JF (2011) Impact of biomedical and biopsychosocial training sessions on the attitudes, beliefs, and recommendations of health care providers about low back pain: a randomised clínical trial. Pain 152: $2557-63$.

67. Holm S, Ljungman G, Åsenlöf P, Söderlund A (2013) How children and adolescents in primary care cope with pain and the biopsychosocial factors that correlate with pain-related disability. Acta Paediatr 102: 1021-6.

68. Andrade PMDO (2010) Evaluation of curriculum guidelines acording to the biopsychosocial perspective of the world health organization (WHO). Avaliação 15: $121-30$.

69. Fisher H (2011) History of the Central Limit Thereom. New York: Springer.

70. Marôco J (2014) Statistical Analysis with SPSS Statistics (6 $6^{\text {th }}$ Edn). Pero Pinheiro, 990.

71. SNS (2017) Servico Nacional De Saude, Portugal.

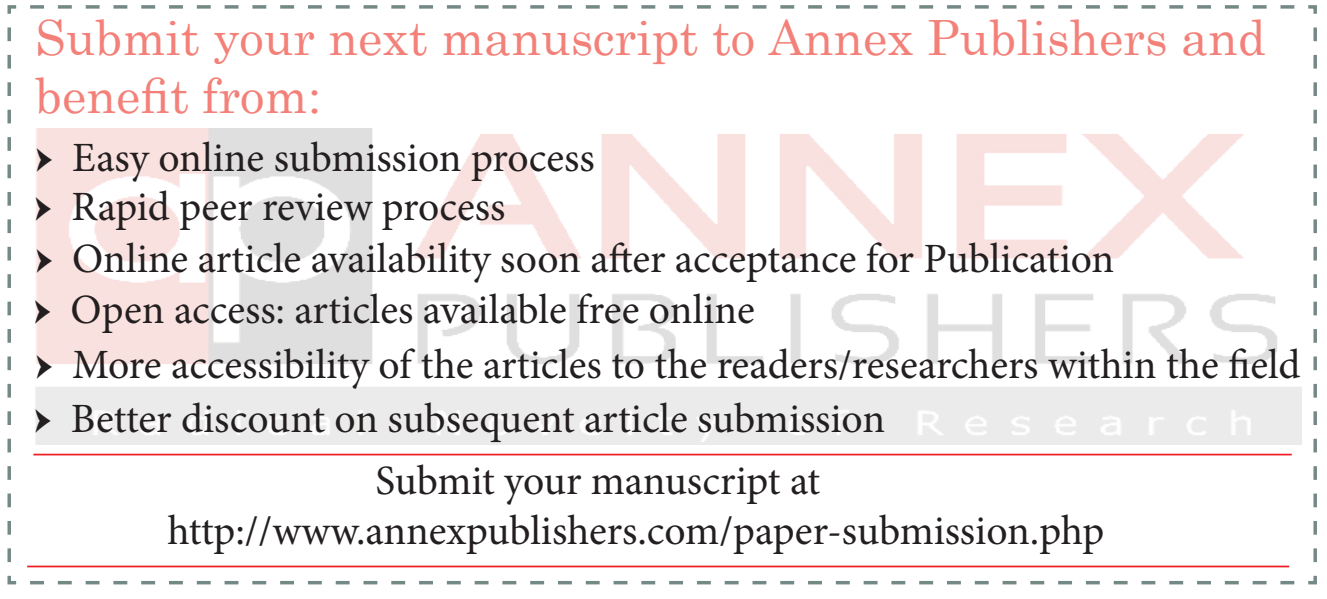

